\title{
Quantitative Lymphoscintigraphy to Predict the Possibility of Lymphedema Development After Breast Cancer Surgery: Retrospective Clinical Study
}

\author{
Paul Kim, MD ${ }^{1}$, Ju Kang Lee, MD, $\mathrm{PhD}^{1}$, Oh Kyung Lim, MD, $\mathrm{PhD}^{1}$, \\ Heung Kyu Park, MD, PhD ${ }^{2}$, Ki Deok Park, MD, PhD ${ }^{1}$
}

Departments of ${ }^{1}$ Rehabilitation Medicine and ${ }^{2}$ Breast Surgery, Gachon University Gil Medical Center, Incheon, Korea

\begin{abstract}
Objective To predict the probability of lymphedema development in breast cancer patients in the early postoperation stage, we investigated the ability of quantitative lymphoscintigraphic assessment.

Methods This retrospective study included 201 patients without lymphedema after unilateral breast cancer surgery. Lymphoscintigraphy was performed between 4 and 8 weeks after surgery to evaluate the lymphatic system in the early postoperative stage. Quantitative lymphoscintigraphy was performed using four methods: ratio of radiopharmaceutical clearance rate of the affected to normal hand; ratio of radioactivity of the affected to normal hand; ratio of radiopharmaceutical uptake rate of the affected to normal axilla (RUA); and ratio of radioactivity of the affected to normal axilla (RRA). During a 1-year follow-up, patients with a circumferential interlimb difference of $2 \mathrm{~cm}$ at any measurement location and a 200-mL interlimb volume difference were diagnosed with lymphedema. We investigated the difference in quantitative lymphoscintigraphic assessment between the nonlymphedema and lymphedema groups.

Results Quantitative lymphoscintigraphic assessment revealed that the RUA and RRA were significantly lower in the lymphedema group than in the non-lymphedema group. After adjusting the model for all significant variables (body mass index, N-stage, T-stage, type of surgery, and type of lymph node surgery), RRA was associated with lymphedema (odds ratio $=0.14 ; 95 \%$ confidence interval, $0.04-0.46 ; \mathrm{p}=0.001$ ).

Conclusion In patients in the early postoperative stage after unilateral breast cancer surgery, quantitative lymphoscintigraphic assessment can be used to predict the probability of developing lymphedema.
\end{abstract}

Keywords Breast cancer, Lymphedema, Lymphoscintigraphy, Quantitative assessment

Received July 26, 2017; Accepted October 13, 2017

Corresponding author: Ki Deok Park

Department of Rehabilitation Medicine, Gachon University Gil Medical Center, 21 Namdong-daero 774beon-gil, Namdong-gu, Incheon 21565, Korea. Tel: +82-32-460-8374, Fax: +82-32-460-3722, E-mail: bduck@gachon.ac.kr

ORCID: Paul Kim (http://orcid.org/0000-0003-2440-5769); Ju Kang Lee (http://orcid.org/0000-0002-8335-9785); Oh Kyung Lim (http://orcid.org/00000002-4286-8073); Heung Kyu Park (http://orcid.org/0000-0002-8284-9221); Ki Deok Park (http://orcid.org/0000-0003-1684-4737).

@ This is an open-access article distributed under the terms of the Creative Commons Attribution Non-Commercial License (http://creativecommons.org/ licenses/by-nc/4.0) which permits unrestricted noncommercial use, distribution, and reproduction in any medium, provided the original work is properly cited. Copyright $\odot 2017$ by Korean Academy of Rehabilitation Medicine 


\section{INTRODUCTION}

Lymphedema can be defined as a chronic and progressive pathologic condition of localized protein-rich fluid accumulation and subcutaneous tissue swelling caused by an impaired lymphatic system [1]. When lymphatic drainage is reduced, water and protein accumulate in local tissues. Secondary lymphedema resulting from an increase in accumulated water is caused by increased colloid osmotic pressure. The reported incidence of secondary lymphedema after breast cancer surgery is approximately $30 \%$ after axillary lymph node dissection (ALND) and 4\%-17\% after sentinel lymph node biopsy (SLNB) $[1,2]$. Other risk factors for lymphedema are younger age, high body mass index (BMI), large tumor size, number of removed lymph nodes (LNs), and the use of radiation therapy or chemotherapy. Among these, the greatest risk factors are BMI $>25 \mathrm{~kg} / \mathrm{m}^{2}$, removal of $>11$ LNs, and use of radiation therapy [3]. However, the most important factor for lymphedema development is the lymphatic drainage status, such as lymphatic obstruction [4].

Once lymphedema has developed, it cannot be completely cured by surgery or medication [5]. In addition, the diagnosis of lymphedema in the early stages is difficult because of the lack of standardized diagnostic criteria. Therefore, the diagnosis and treatment of secondary lymphedema after breast cancer surgery are delayed [6]. If early diagnosis or prediction of lymphedema were possible, the development of secondary lymphedema could be avoided or controlled [7]. Therefore, adopting appropriate preventive measures in patients who have a high risk for lymphedema is important [8-10]. However, four large-scale prospective cohort studies did not clearly reveal the relationship between risk factors and lymphedema development [3,11-13]. Therefore, objective and quantitative tests or parameters are necessary to predict a high risk for lymphedema development in patients who have undergone breast cancer surgery.

Lymphoscintigraphy is the primary imaging modality used to diagnose lymphedema [14-17]. The technique is a reliable, reproducible, and noninvasive diagnostic tool for lymphedema without known adverse effects. It evaluates severity by visualizing the lymphatic system, such as lymphatic channels and regional LNs [18]. Until now, lymphoscintigraphic findings have generally been sub- ject to qualitative interpretations. Qualitative lymphoscintigraphic analysis helps reveal impairments of the lymphatic system, such as obstruction of lymphatic flow, collateral lymphatic flow, dermal backflow, vanished or reduced LNs, and dilated or no visualized lymphatic system $[19,20]$. Recently, quantitative lymphoscintigraphy was suggested as being more sensitive than qualitative lymphoscintigraphy to confirm the diagnosis of lymphedema [6]. It may be particularly sensitive in patients with mild symptoms, which make early diagnosis difficult.

We hypothesized that lymphoscintigraphy could help predict lymphedema development in patients in the early postoperative stage. The aim of this study was to evaluate whether early quantitative lymphoscintigraphic assessment can predict the probability of lymphedema development in patients after breast cancer surgery.

\section{MATERIALS AND METHODS}

\section{Patients}

The inclusion criteria for this study were (1) women over the age of 18 years, (2) history of unilateral breast cancer surgery, (3) no prior clinical diagnosis of lymphedema, and (4) clinical follow-up of more than 1 year after lymphoscintigraphy. The exclusion criteria were (1) history of bilateral breast cancer, (2) history of bilateral trauma in the arms, (3) previous chemotherapy or radiotherapy, (4) previous history or presence of certain comorbidities (metastasis, lymphatic disease, or infectious state of the arm), and (5) systemic edema due to chemotherapy.

Clinical and lymphoscintigraphy data were retrospectively obtained from 201 identified patients at the Department of Rehabilitation Medicine at Gachon University Gil Medical Center who had undergone unilateral breast cancer surgery between July 2013 and November 2016 . Among them, 41 patients developed lymphedema during a 1-year follow-up after breast cancer surgery, while 160 patients did not. This research was approved by the Institutional Review Board of Gachon University Gil Medical Center (No. GCIRB2013-160).

\section{Lymphoscintigraphy protocol}

All patients underwent lymphoscintigraphy between 4 and 8 weeks after surgery to evaluate the lymphatic sys- 
tem in the early postoperative stage. Lymphoscintigraphy was performed at least 4 weeks after surgery to exclude temporary edema occurring immediately after surgery. All patients visited the outpatient clinic regularly every 4 weeks for 1 year to confirm the occurrence of lymphedema. We quantitatively analyzed differences in lymphoscintigraphy performed in the early postoperative period between patients with and without lymphedema during that time.

The radiopharmaceutical was radiolabeled Tc-99m phytate $(500 \mu \mathrm{Ci})$. After subcutaneous injection of particles into two sites at the first and second interdigital spaces of the dorsum of each hand by using a 25 -gauge needle, the patients were immediately encouraged to perform repeated gripping exercises for 20 minutes to induce lymphatic flow in the upper limbs. Images of both hands were acquired 5 and 20 minutes after injection. Images of the axillae were acquired 30 and 60 minutes after injection by using a dual-head gamma camera (Symbia; Siemens Healthcare Sector, Erlangen, Germany).

\section{Diagnostic criteria for lymphedema}

The circumferences of five areas in the upper extremities were measured bilaterally using a flexible tape measure without any pressure applied perpendicular to the axis of the arm [21]. The upper arm was measured at the midpoint between the lateral epicondyle of the humerus and the acromion of the shoulder, and at a point $15 \mathrm{~cm}$ above the lateral epicondyle of the humerus. The elbow was measured at the lateral epicondyle of the humerus. The forearm was measured at the midpoint between the tip of the ulnar styloid process and the lateral epicondyle of the humerus, and at a point $10 \mathrm{~cm}$ below the lateral epicondyle of the humerus (Fig. 1).

The volume of each upper arm was measured using plethysmography. Each arm was inserted into the plethysmograph to a point $15 \mathrm{~cm}$ above the lateral epicondyle of the humerus.

In all patients, the circumferences and volume were initially measured before lymphoscintigraphy. The measurements were repeated every 4 weeks for at least 1 year after the initial measurement. The measurements were blindly evaluated in consensus by two rehabilitation nurses trained to perform the circumferential and volume measurements, whose mean values were obtained for accuracy. Lymphedema was diagnosed when the

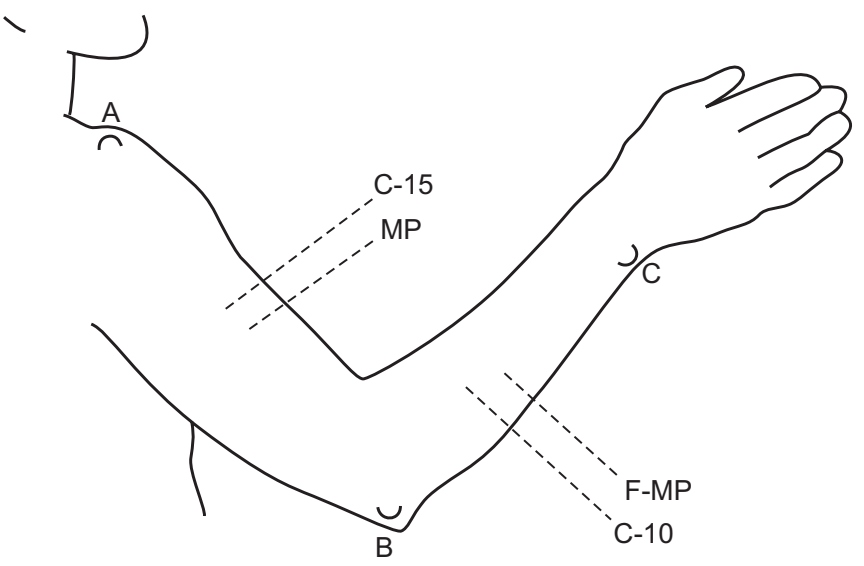

Fig. 1. Points for objective circumference measurements to diagnose lymphedema, as suggested by Starritt et al. [21]. MP, midpoint between the lateral epicondyle of the humerus and the acromion of the shoulder; C-15, $15 \mathrm{~cm}$ above the lateral epicondyle of the humerus; F-MP, midpoint between the ulnar styloid process and the lateral epicondyle of the humerus; $\mathrm{C}-10,10 \mathrm{~cm}$ below the lateral epicondyle of the humerus; $\mathrm{A}$, acromion; $\mathrm{B}$, lateral epicondyle; C, ulnar styloid process.

circumferential interlimb difference at any location was $>2 \mathrm{~cm}$ and the interlimb volume difference was $>200 \mathrm{~mL}$ compared to the previous measurements.

\section{Regions of interest and quantitative lymphoscintigraphic assessment}

Regions of interest (ROIs) were drawn on both hands with circular boundaries of the same size to cover radiopharmaceutical uptake areas at the injection sites. Images were acquired 5 and 20 minutes after injection to compare the calculated clearance rate from the injection site (Fig. 2). The clearance rate from the injection site was obtained using the following equation [6]:

$$
\text { Clearance rate }=\frac{(\text { IIS } \times 0.97)-\text { LIS }}{\text { IIS } \times 0.97},
$$

where IIS is the initial uptake at the injection site at 5 minutes after injection, LIS is the late uptake at the injection site at 20 minutes after injection, and 0.97 is the technetium correction factor.

Counts from the total amount remaining at the injection site were determined from the images acquired 20 minutes after injection. Subsequently, the ratio of radioactivity of the affected to normal hand (RRH) in the ROI of the injection site was calculated. As the absolute 


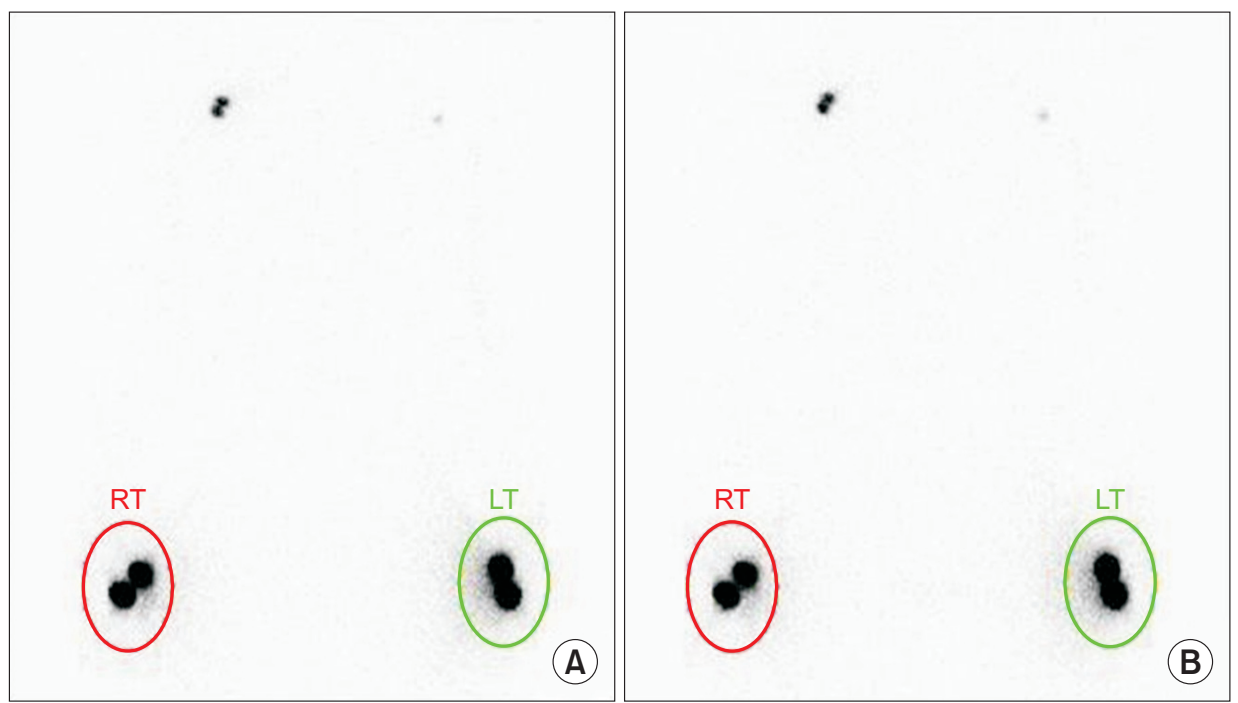

Fig. 2. Typical images of qualitative lymphoscintigraphy of the upper arms of a patient after breast cancer surgery. The images were acquired approximately 5 minutes (A) and 20 minutes (B) after injection and used to calculate the clearance rate from the injection site.

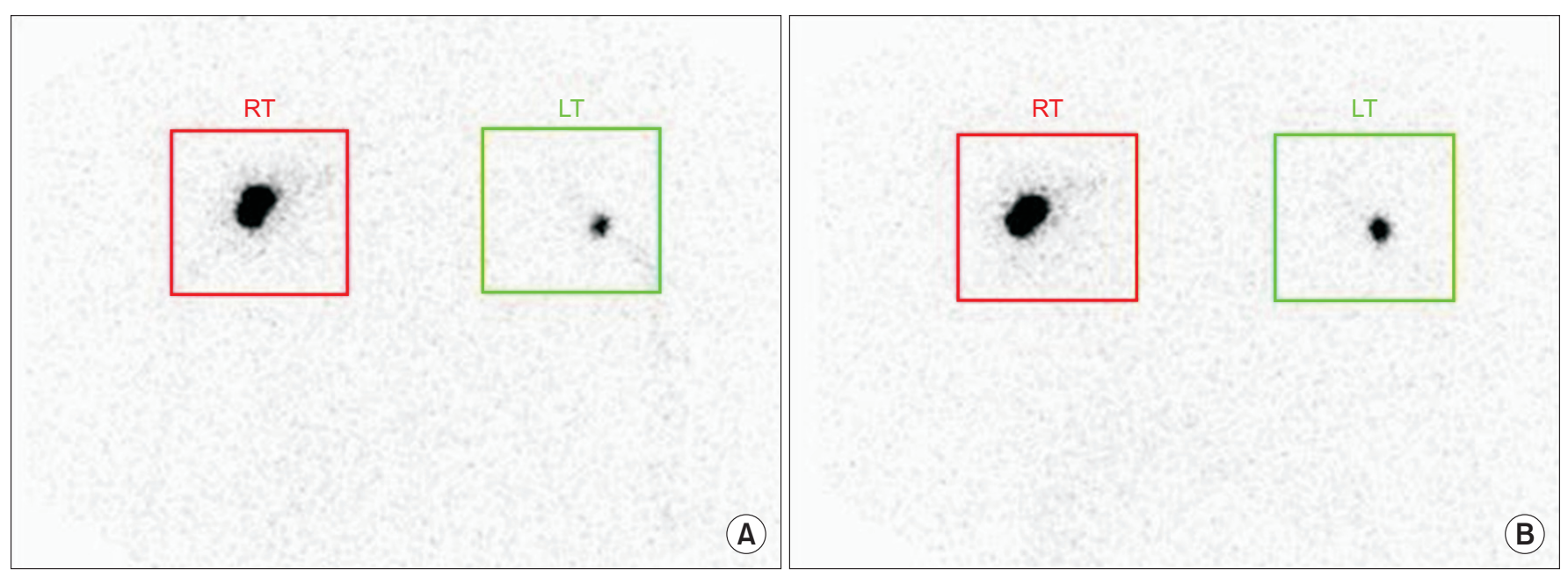

Fig. 3. Typical images of qualitative lymphoscintigraphy of the upper arms of a patient after breast cancer surgery. The images were acquired approximately 30 minutes (A) and 60 minutes (B) after injection and used to calculate the uptake rate of the axillary nodes. RT, right; LT, left.

remaining amount varied for each individual, we compared the ratio of radioactivity of the affected and normal sides [6].

Symmetrical ROIs were placed over the axillae on each lymphoscintigram acquired approximately 30 and 60 minutes after injection to calculate the uptake rate of the axillary nodes (Fig. 3). Then, the ratio of radiopharmaceutical uptake rate of the affected to normal axilla (RUA) was calculated. The uptake rate of the axillary nodes was obtained using the following equation [6]:

$$
\text { Uptake rate }=\frac{\text { Late axillary node uptake }}{\text { IIS } \times 0.89},
$$

where IIS is the initial uptake at the injection site and 0.89 is the technetium correction factor.

The total absorbed amount in the axillary nodes was also determined from the image acquired 60 minutes after injection. Finally, the ratio of radioactivity of the affected to normal axilla (RRA) in the axillary ROIs was calculated. Quantitative lymphoscintigraphic analysis was performed in patients who received SLNB and patients who received ALND, and analyzed in all patients.

\section{Statistical analyses}

All statistical analyses were performed using IBM SPSS Statistics for Windows ver. 21.0 (IBM Corp., Armonk, 
Table 1. Characteristics of patients with and without lymphedema after breast cancer surgery

\begin{tabular}{|c|c|c|c|}
\hline & Non-lymphedema $(n=160)$ & Lymphedema $(n=41)$ & p-value \\
\hline Age (yr) & $54.21 \pm 10.08$ & $53.56 \pm 9.03$ & 0.707 \\
\hline $\operatorname{BMI}\left(\mathrm{kg} / \mathrm{m}^{2}\right)$ & $23.33 \pm 3.01$ & $25.88 \pm 3.98$ & $<0.001^{*}$ \\
\hline \multicolumn{4}{|l|}{ Location of tumor } \\
\hline Right & $81(50.6)$ & $17(41.5)$ & 0.295 \\
\hline Left & $79(49.4)$ & $24(58.5)$ & \\
\hline \multicolumn{4}{|l|}{ Stage } \\
\hline I & $19(11.9)$ & $3(7.3)$ & 0.058 \\
\hline II & $58(36.3)$ & $10(24.4)$ & \\
\hline III & $65(40.6)$ & $17(41.5)$ & \\
\hline IV & $18(11.3)$ & $11(26.8)$ & \\
\hline \multicolumn{4}{|l|}{$\mathrm{N}$-stage } \\
\hline No & $113(70.6)$ & $25(61.0)$ & $0.023^{*}$ \\
\hline N1 & $32(20.0)$ & $7(17.1)$ & \\
\hline $\mathrm{N} 2$ & $12(7.5)$ & $4(9.8)$ & \\
\hline N3 & $3(1.9)$ & $5(12.2)$ & \\
\hline \multicolumn{4}{|l|}{ T-stage } \\
\hline T0 & $19(11.9)$ & $3(7.3)$ & $0.002^{*}$ \\
\hline $\mathrm{T} 1$ & $70(43.8)$ & $12(29.3)$ & \\
\hline $\mathrm{T} 2$ & $61(38.1)$ & $16(39.0)$ & \\
\hline T3 & $8(5.0)$ & $10(24.4)$ & \\
\hline $\mathrm{T} 4$ & $2(1.3)$ & $0(0.0)$ & \\
\hline \multicolumn{4}{|l|}{ Radiation therapy } \\
\hline Yes & $123(76.9)$ & $31(75.6)$ & 0.864 \\
\hline No & $37(23.1)$ & $10(24.4)$ & \\
\hline \multicolumn{4}{|l|}{ Chemotherapy } \\
\hline Yes & $88(55.0)$ & $26(63.4)$ & 0.332 \\
\hline No & $72(45.0)$ & $15(36.6)$ & \\
\hline \multicolumn{4}{|l|}{ Type of surgery } \\
\hline BCS & $134(83.8)$ & $25(61.0)$ & $0.004^{*}$ \\
\hline $\mathrm{TM}$ & $9(5.6)$ & $4(9.8)$ & \\
\hline MRM & $17(10.6)$ & $12(29.3)$ & \\
\hline \multicolumn{4}{|c|}{ Type of lymph node surgery } \\
\hline SLNB & $113(70.6)$ & $21(51.2)$ & $0.019 *$ \\
\hline ALND & $47(29.4)$ & $20(48.8)$ & \\
\hline \multicolumn{4}{|c|}{ Number of removed lymph nodes } \\
\hline SLNB & $3.87 \pm 1.96$ & $4.00 \pm 1.87$ & 0.775 \\
\hline ALND & $19.77 \pm 9.87$ & $18.25 \pm 6.94$ & 0.535 \\
\hline SLNB and ALND & $8.99 \pm 9.24$ & $11.32 \pm 8.68$ & 0.717 \\
\hline
\end{tabular}

Values are presented as mean \pm standard deviation or number (\%).

BMI, body mass index; BCS, breast-conserving surgery; TM, total mastectomy; MRM, modified radical mastectomy; SLNB, sentinel lymph node biopsy; ALND, axillary lymph node dissection.

${ }^{*} \mathrm{p}<0.05$. 
NY, USA). An independent t-test and a chi-square test were used to compare the general characteristics of the patients and lymphoscintigraphic findings between patients with and without lymphedema. Independent ttests were used to confirm statistical differences between the lymphedema and non-lymphedema groups in age, BMI, and number of removed LNs. A chi-square test was used to assess the correlations between tumor location, breast cancer stage, radiation therapy, chemotherapy, type of surgery, type of LN surgery, and lymphedema development. After the analysis, all predefined variables were included in a multivariate logistic regression analysis by using a forward selection procedure to identify the independent risk factors for lymphedema. The predefined variables were age, BMI, location of tumor, stage, $\mathrm{N}$-stage, $\mathrm{T}$-stage, radiation therapy, chemotherapy, type of surgery, type of LN surgery, number of removed LNs, the ratio of radiopharmaceutical clearance rate of the affected to normal hand (RCH), RRH, RUA, and RRA. Forward selection began with a model that contained the most important variables in the initial analysis; variables were continuously added until none of the remaining variables were significant when added to the model. The odds ratio (OR) and $95 \%$ confidence interval (CI) were calculated for every variable; a $p$-value $<0.05$ was considered significant.

\section{RESULTS}

\section{General characteristics}

In total, 468 patients underwent breast cancer surgery between July 2013 and November 2016. Of these, 201 patients did not meet the inclusion criteria and 267 patients did. Of the latter, 204 patients agreed to participate, and 201 visited the outpatient clinic over 1 year. Three patients dropped out. Finally, 201 patients who had undergone breast cancer surgery were included.

All patients were women (mean age, $54.1 \pm 9.8$ years). Forty one had been diagnosed with secondary lymphedema within 1 year after surgery. No statistically significant differences were found in age, location of tumor, stage, radiotherapy or chemotherapy use, and number of removed LNs. In contrast, there were significant differences in BMI, N-stage, T-stage, type of surgery, and type of LN surgery (Table 1).

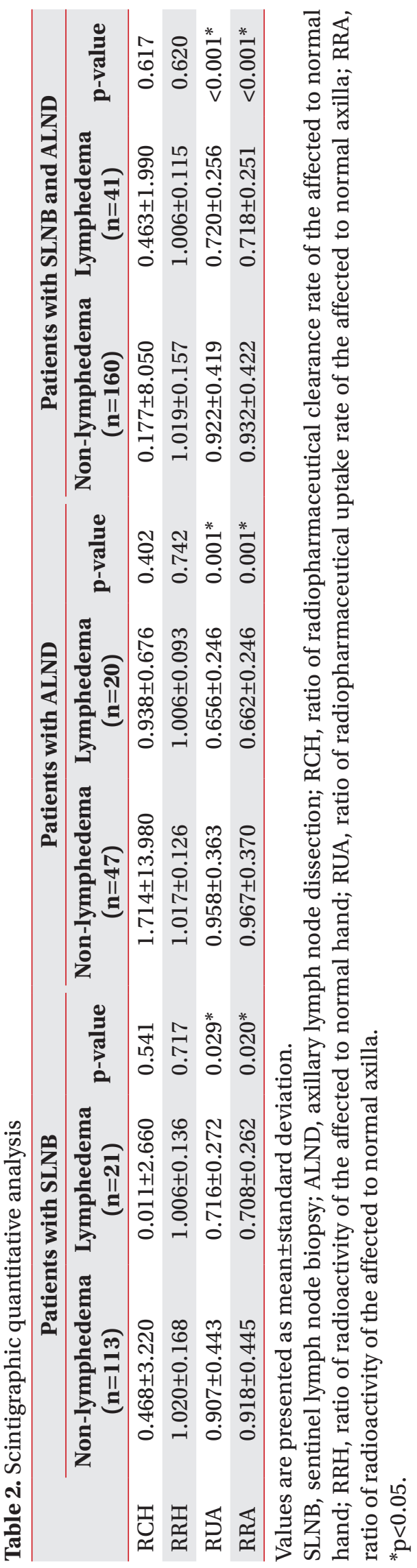


Correlation between quantitative lymphoscintigraphic assessment and lymphedema development

In patients who received SLNB, RUA was significantly lower in patients with lymphedema $(0.736 \pm 0.272)$ than in those without $(0.907 \pm 0.443 ; \mathrm{p}=0.029)$. RRA was significantly lower in patients with lymphedema $(0.728 \pm 0.262)$ than in those without $(0.918 \pm 0.445 ; \mathrm{p}=0.020)$ on lymphoscintigrams acquired 60 minutes after injection (Table 2).

Similar results were obtained in patients who received ALND. RUAs were $0.676 \pm 0.246$ and $0.958 \pm 0.363$ in patients with and without lymphedema, respectively $(\mathrm{p}=0.001)$. RRAs were $0.672 \pm 0.246$ and $0.967 \pm 0.370$ in patients with and without lymphedema, respectively ( $\mathrm{p}=0.001)$ (Table 2).

The significance increased when all patients were

Table 3. Multivariate stepwise logistic regression analysis of variables associated with lymphedema after breast cancer surgery

\begin{tabular}{lll}
\hline \multicolumn{1}{c}{ Variable } & OR $(95 \%$ CI $)$ & p-value \\
\hline BMI & $1.29(1.14-1.46)$ & $<0.001^{*}$ \\
Type of surgery & & \\
MRM & $7.96(2.81-22.53)$ & $<0.001^{*}$ \\
RRA & $0.14(0.04-0.46)$ & $<0.001^{*}$ \\
\hline
\end{tabular}

OR, odds ratio; CI, confidence interval; BMI, body mass index; MRM, modified radical mastectomy; RRA, ratio of radioactivity of the affected to normal axilla. ${ }^{*} \mathrm{p}<0.05$.

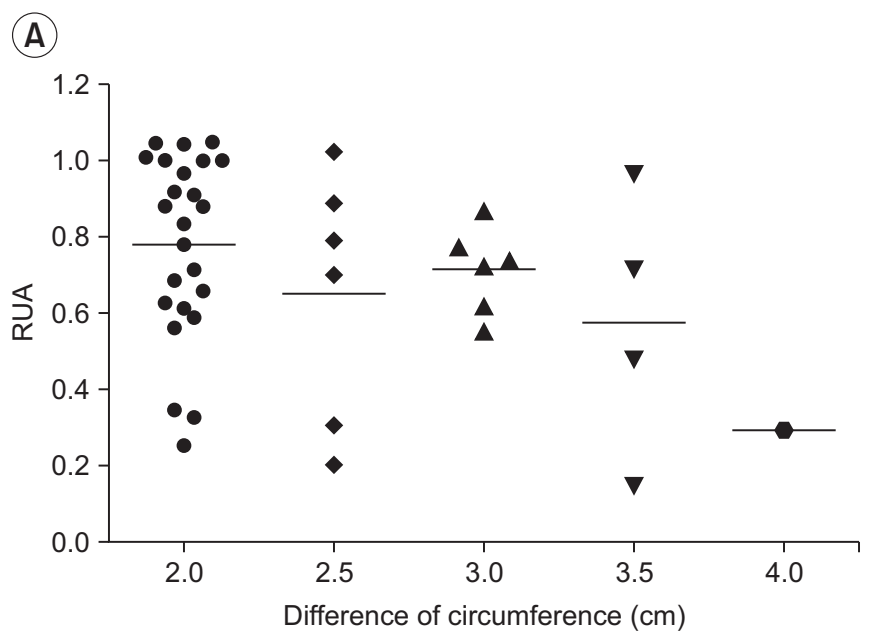

analyzed. RUAs were $0.720 \pm 0.256$ and $0.922 \pm 0.419$ for patients with and without lymphedema, respectively $(\mathrm{p}<0.001)$. RRAs were $0.718 \pm 0.251$ and $0.932 \pm 0.422$ in patients with and without lymphedema, respectively $(\mathrm{p}<0.001)$ (Table 2).

BMI, type of surgery, and RRA were confirmed as independent risk factors for lymphedema development after multivariate logistic regression analysis using a forward selection procedure. Among quantitative lymphoscintigraphic assessment, RRA was associated with lymphedema (OR=0.14; 95\% CI, 0.04-0.46; $\mathrm{p}<0.001$ ) (Table 3).

\section{Correlation between quantitative lymphoscintigraphy and maximum circumference difference}

The relationship between the RUA and maximum circumference difference between the upper arms in patients with lymphedema was not statistically significant but showed an inverse correlation $(\mathrm{p}=0.19)$. The relationship between the RRA and maximum circumference difference showed similar results $(\mathrm{p}=0.18)$. The inverse correlation was not statistically significant, but a similar result was obtained in the volume analysis (Fig. 4).

\section{DISCUSSION}

To our knowledge, this is the first study to evaluate the usefulness of early lymphoscintigraphy after breast cancer surgery for predicting the probability of lymphedema
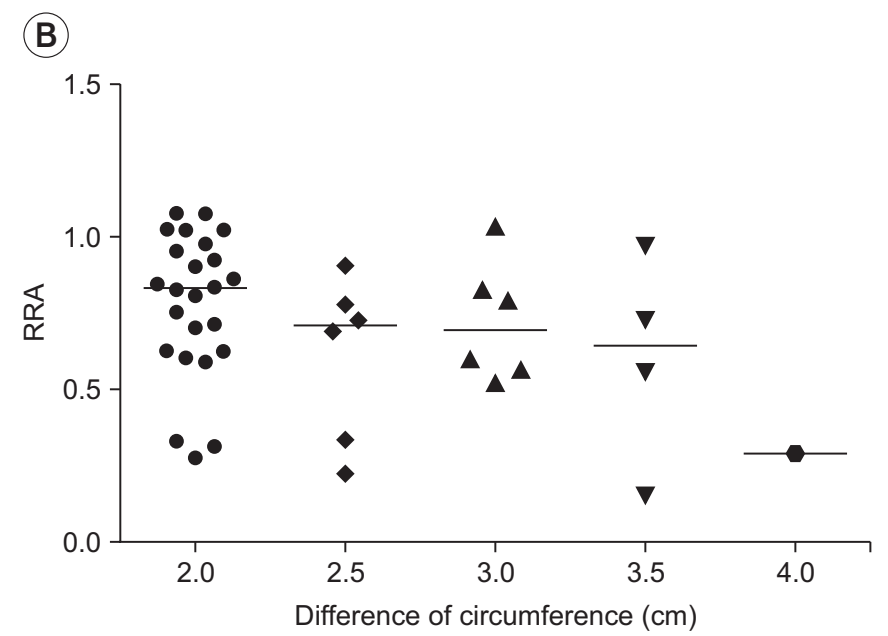

Fig. 4. Correlation between quantitative lymphoscintigraphy analysis and difference in circumference. The maximum circumference difference between the upper arms of patients with lymphedema show a significant inverse correlation with the RUA (A) and the RRA (B). RUA, ratio of radiopharmaceutical uptake rate of the affected to normal axilla; RRA, ratio of radioactivity of the affected to normal axilla. 
development. Our results suggest that quantitative lymphoscintigraphic analysis, especially RRA, correlated with the probability of lymphedema development. Early lymphoscintigraphic evaluation of lymphatics after breast cancer surgery can help formulate preventative management and follow-up plans, and potentially improve longterm outcomes.

Many studies have investigated the medical and demographic risk factors for lymphedema after breast cancer treatment. Among them, ALND is the most recognized risk factor [22]. Previous studies have also reported other risk factors, such as the number of nodes involved in the cancer, radiotherapy administered to the axilla, supraclavicular nodes, and increased body weight [23-25]. The relationship between the risk of lymphedema and the number of nodes removed is still debatable [26]. Previous studies have reported that the number of removed LNs increases the risk of lymphedema [27-29]. In contrast, other retrospective studies have reported the number of removed nodes was not significantly associated with lymphedema [30,31]. The risk of lymphedema is more related to the magnitude of lymphatic destruction and an individual patient's ability to re-establish collateral lymphatic circulation than to the number of removed LNs. Therefore, the number of removed LNs alone may not be sufficient to determine the risk of lymphedema [26]. Moreover, the relationship between lymphedema and chemotherapy remains unproven and controversial, with some studies reporting a relationship $[12,13,22]$ and other studies reporting no clear relationship [32-34]. It is unclear whether chemotherapy is directly associated with lymphedema because chemotherapy is associated with a higher cancer stage. No statistically significant correlation was observed between chemotherapy and lymphedema development. In this study, all the patients treated using chemotherapy received it postoperatively and not preoperatively.

These known risk factors do not accurately predict the probability of lymphedema development [22]. Wang et al. [35] suggested a scoring system comprised of five pathological factors to predict arm lymphedema risk: level of ALND, radiotherapy, surgical infection/seroma/early edema, history of hypertension, and surgery of the dominant arm. As these risk factors have a combined impact on lymphedema development rather than independent impacts, it is important to evaluate lymphatic function rather than assess each risk factor. Furthermore, this study highlights the importance of quantifying lymphatic function for assessing lymphedema development.

Lymphoscintigraphy has become the standard for evaluating lymphedema [14-17]. Lymphoscintigraphy offers an objective and reliable approach for diagnosing and identifying the severity of lymphedema by visualizing an impaired lymphatic system. However, these abnormal findings are not always present in patients with lymphedema and may be overlooked during qualitative interpretation [6]. The quantitative analysis of lymphoscintigraphy has the advantage of detecting subtle changes in the lymphatic system that may be overlooked during qualitative analysis. These subtle changes may cause lymphedema over time.

Recently, many studies have used quantitative analysis of lymphoscintigraphy to diagnose lymphedema. Dalia et al. [6] suggested that quantitative lymphoscintigraphic analysis might be a sensitive technique for diagnosing lymphedema in normal patients or those with mild symptoms. Carena et al. [36] reported that quantitative lymphoscintigraphy is an effective indicator of early changes in lymphatic pathophysiology and revealed that lymphedema generally develops after predisposing lymphatic pathophysiology. Other studies have reported that the mean transit time of tracer can reliably discriminate between the presence and absence of lymphedema and that it is associated with disease severity $[37,38]$.

Our study showed that lymphoscintigraphy can be used as a diagnostic as well as prognostic tool for lymphedema. The RCH and RRH measured at the hand were not significantly different between patients with and without lymphedema, but the RUA and RRA measured at the axilla were statistically significant. Presently, inguinal node uptake was significantly different between patients with and without lymphedema, but without a significant difference in the clearance rate from the injection site of the foot [6]. The following are the possible reasons for these observations. First, the clearance rate from the injection site is relatively rapid. Therefore, the clearance rate from the distal part could not reveal the clinical status of the entire limb in cases of minor or focal lymphatic system changes [39]. Second, the disturbance of lymphatic flow is the main cause of lymphedema and the lymphatic system in the axillary area is directly damaged during breast cancer surgery. Hence, the uptake rate in the axillary 
area could be disturbed earlier than is the clearance rate change in the hand area.

Using the predictive factors of quantitative lymphoscintigraphic analysis, such as lower RRA, clinicians could plan a short-term follow-up schedule to evaluate the possibility of developing secondary lymphedema. These results have important clinical implications in preventing lymphedema, which is a chronic and difficult-to-cure disease. In addition, clinicians could strongly encourage such patients to consider the need for short-term followup and more careful preventive management.

This study has several limitations. First, there was a selection bias because of the single-center design. Second, the number of patients with lymphedema was small; hence, the relationship between quantitative lymphoscintigraphic analysis and maximum circumference difference may not be statistically significant. Further studies should include a larger number of patients with lymphedema after breast cancer surgery. Third, because of the possibility of developing lymphedema after a long period, longer follow-up periods are warranted to analyze the long-term relationship between quantitative lymphoscintigraphic assessment and lymphedema development. Fourth, we confirmed that the RUA and RRA were predictive indicators of lymphedema, but we could not find accurate cut-off levels for the RUA and RRA for predicting lymphedema development. We plan to further investigate the cut-off levels of predictive indicators such as the RUA and RRA depending on the method of lymph node resection. Finally, patient characteristics (e.g., physical activity or subjective symptoms) that could affect lymphedema development were not considered; analyzing these variables will strengthen future research findings.

In conclusion, our results suggest that early lymphoscintigraphy after breast cancer surgery may be useful in predicting lymphedema development. RRA was associated with the probability of developing lymphedema. We suggest that early lymphoscintigraphy after breast cancer surgery is important for evaluating the potential for lymphedema development and formulating therapeutic and follow-up plans.

\section{CONFLICT OF INTEREST}

No potential conflict of interest relevant to this article was reported.

\section{REFERENCES}

1. Warren AG, Brorson H, Borud LJ, Slavin SA. Lymphedema: a comprehensive review. Ann Plast Surg 2007; 59:464-72.

2. McLaughlin SA, Wright MJ, Morris KT, Giron GL, Sampson MR, Brockway JP, et al. Prevalence of lymphedema in women with breast cancer 5 years after sentinel lymph node biopsy or axillary dissection: objective measurements. J Clin Oncol 2008;26:5213-9.

3. Dominick SA, Madlensky L, Natarajan L, Pierce JP. Risk factors associated with breast cancer-related lymphedema in the WHEL Study. J Cancer Surviv 2013; 7:115-23.

4. Rezende LF, Rocha AVR, Gomes CS. Risk factors for breast cancer related lymphedema. J Vasc Bras 2010; 9:233-8.

5. Sarri AJ, Moriguchi SM, Dias R, Peres SV, DA Silva ET, Koga KH, et al. Physiotherapeutic stimulation: Early prevention of lymphedema following axillary lymph node dissection for breast cancer treatment. Exp Ther Med 2010;1:147-152.

6. Dalia RM, Martins GR, Barbosa R, de Lima CF, Siqueira CF. Qualitative and quantitative lymphoscintigraphy in the evaluation of lower limbs lymphedema. Braz Arch Biol Technol 2005;48:159-62.

7. Linnitt N. Lymphoedema: recognition, assessment and management. Br J Community Nurs 2005;10:S206.

8. Deltombe T, Jamart J, Recloux S, Legrand C, Vandenbroeck N, Theys S, et al. Reliability and limits of agreement of circumferential, water displacement, and optoelectronic volumetry in the measurement of upper limb lymphedema. Lymphology 2007;40:26-34.

9. Soo JK, Bicanic TA, Heenan S, Mortimer PS. Lymphatic abnormalities demonstrated by lymphoscintigraphy after lower limb cellulitis. Br J Dermatol 2008; 158:1350-3.

10. Bernas MJ, Askew RL, Armer JM, Cormier JN. Lymphedema: how do we diagnose and reduce the risk of this dreaded complication of breast cancer treatment? Curr Breast Cancer Rep 2010;2:53-8.

11. Kwan ML, Darbinian J, Schmitz KH, Citron R, Partee P, Kutner SE, et al. Risk factors for lymphedema in 
a prospective breast cancer survivorship study: the pathways study. Arch Surg 2010;145:1055-63.

12. Ahmed RL, Schmitz KH, Prizment AE, Folsom AR. Risk factors for lymphedema in breast cancer survivors, the Iowa Women's Health Study. Breast Cancer Res Treat 2011;130:981-91.

13. Norman SA, Localio AR, Kallan MJ, Weber AL, Torpey HA, Potashnik SL, et al. Risk factors for lymphedema after breast cancer treatment. Cancer Epidemiol Biomarkers Prev 2010;19:2734-46.

14. Szuba A, Shin WS, Strauss HW, Rockson S. The third circulation: radionuclide lymphoscintigraphy in the evaluation of lymphedema. J Nucl Med 2003;44:43-57.

15. Yuan Z, Chen L, Luo Q, Zhu J, Lu H, Zhu R. The role of radionuclide lymphoscintigraphy in extremity lymphedema. Ann Nucl Med 2006;20:341-4.

16. Sadeghi R, Kazemzadeh G, Keshtgar M. Diagnostic application of lymphoscintigraphy in the management of lymphoedema. Hell J Nucl Med 2010;13:6-10.

17. International Society of Lymphology. The diagnosis and treatment of peripheral lymphedema: 2013 Consensus Document of the International Society of Lymphology. Lymphology 2013;46:1-11.

18. Szuba A, Rockson SG. Lymphedema: classification, diagnosis and therapy. Vasc Med 1998;3:145-56.

19. Ter SE, Alavi A, Kim CK, Merli G. Lymphoscintigraphy: a reliable test for the diagnosis of lymphedema. Clin Nucl Med 1993;18:646-54.

20. Weissleder H, Weissleder R. Lymphedema: evaluation of qualitative and quantitative lymphoscintigraphy in 238 patients. Radiology 1988;167:729-35.

21. Starritt EC, Joseph D, McKinnon JG, Lo SK, de Wilt JH, Thompson JF. Lymphedema after complete axillary node dissection for melanoma: assessment using a new, objective definition. Ann Surg 2004;240:866-74.

22. Hayes SC, Janda M, Cornish B, Battistutta D, Newman B. Lymphedema after breast cancer: incidence, risk factors, and effect on upper body function. J Clin Oncol 2008;26:3536-42.

23. DiSipio T, Rye S, Newman B, Hayes S. Incidence of unilateral arm lymphoedema after breast cancer: a systematic review and meta-analysis. Lancet Oncol 2013;14:500-15.

24. Tsai RJ, Dennis LK, Lynch CF, Snetselaar LG, Zamba GK, Scott-Conner C. The risk of developing arm lymphedema among breast cancer survivors: a meta- analysis of treatment factors. Ann Surg Oncol 2009;16: 1959-72.

25. Chandra RA, Miller CL, Skolny MN, Warren LE, Horick N, Jammallo LS, et al. Radiation therapy risk factors for development of lymphedema in patients treated with regional lymph node irradiation for breast cancer. Int J Radiat Oncol Biol Phys 2015;91:760-4.

26. McLaughlin SA. Lymphedema: separating fact from fiction. Oncology (Williston Park) 2012;26:242-9.

27. Herd-Smith A, Russo A, Muraca MG, Del Turco MR, Cardona G. Prognostic factors for lymphedema after primary treatment of breast carcinoma. Cancer 2001; 92:1783-7.

28. Kiel KD, Rademacker AW. Early-stage breast cancer: arm edema after wide excision and breast irradiation. Radiology 1996;198:279-83.

29. Paskett ED, Naughton MJ, McCoy TP, Case LD, Abbott JM. The epidemiology of arm and hand swelling in premenopausal breast cancer survivors. Cancer Epidemiol Biomarkers Prev 2007;16:775-82.

30. Ozaslan C, Kuru B. Lymphedema after treatment of breast cancer. Am J Surg 2004;187:69-72.

31. Hinrichs CS, Watroba NL, Rezaishiraz H, Giese W, Hurd T, Fassl KA, et al. Lymphedema secondary to postmastectomy radiation: incidence and risk factors. Ann Surg Oncol 2004;11:573-80.

32. Shih YC, Xu Y, Cormier JN, Giordano S, Ridner SH, Buchholz TA, et al. Incidence, treatment costs, and complications of lymphedema after breast cancer among women of working age: a 2-year follow-up study. J Clin Oncol 2009;27:2007-14.

33. Yen TW, Fan X, Sparapani R, Laud PW, Walker AP, Nattinger AB. A contemporary, population-based study of lymphedema risk factors in older women with breast cancer. Ann Surg Oncol 2009;16:979-88.

34. Meeske KA, Sullivan-Halley J, Smith AW, McTiernan A, Baumgartner KB, Harlan LC, et al. Risk factors for arm lymphedema following breast cancer diagnosis in Black women and White women. Breast Cancer Res Treat 2009;113:383-91.

35. Wang L, Li HP, Liu AN, Wang DB, Yang YJ, Duan YQ, et al. A scoring system to predict arm lymphedema risk for individual Chinese breast cancer patients. Breast Care (Basel) 2016;11:52-6.

36. Carena M, Campini R, Zelaschi G, Rossi G, Aprile C, Paroni G. Quantitative lymphoscintigraphy. Eur J Nucl 
Med 1988;14:88-92.

37. Toyserkani NM, Hvidsten S, Tabatabaeifar S, Simonsen JA, Hoilund-Carlsen PF, Sorensen JA. Tc-99mhuman serum albumin transit time as a measure of arm breast cancer-related lymphedema. Plast Reconstr Surg Glob Open 2017;5:e1362.

38. Simonsen J, Hvidsten S, Hoilund-Carlsen PF, Sorensen
J, Toyserkani N. Quantification of breast cancer-related lymphedema of the upper limbs. J Nucl Med 2017; 58(Suppl 1):468.

39. Witte CL, Witte MH, Unger EC, Williams WH, Bernas MJ, McNeill GC, et al. Advances in imaging of lymph flow disorders. Radiographics 2000;20:1697-719. 